\title{
Characteristic and Relevant Factors Analysis of Lightning Disaster in Hainan Island
}

\author{
Yi Gao, Fangcong Zhou, Changxiong Wei \\ Lightning Protection Center of Hainan Province, Haikou, 570203, China
}

\begin{abstract}
Characteristics of lightning disaster in Hainan Island from 1999 to 2011 are analyzed by using nationwide lightning disaster data, thunderstorm data, lightning location data, and statistical yearbook of Hainan Province. The results show that 727 lightning disaster accidents are reported, which result in 405 casualties including 157 deaths and 248 injuries. Lightning casualty ratio is $1.58: 1$. The lightning disasters of Hainan Island mainly occur between 1:00pm and 6:00pm from April to September, which is in accord with lightning activity of Hainan Island. Haikou and Qiongzhong report the most lightning disaster accidents. Lightning disaster with casualty usually occur in field, simple shed, rural residential, water area and under the tree in sequence. Lightning disaster with damages occur most frequently in the power, petrochemical industries and three others, which account for $22.2 \%$ of the lightning disaster with damage. The hotel accounted for the largest proportion $(34.7 \%)$ of the direct economic losses caused by lightning disaster. Lightning disasters with casualty and damage have no significant correlation with thunderstorm day, but lightning disasters with casualty and damage are positively correlated with life fragile module and economic vulnerability module.
\end{abstract}

Keywords-lightning disaster; spatial and temporal characteristic; lightning casualty; lightning damage.

\section{INTRODUCTION}

Lightning disaster is one of the 10 most serious natural disasters released by the Committee of UN International Decade for Natural Disaster Reduction. The researchers have made in-depth analysis on characteristics of lightning disaster and lightning casualties in America. Thunder and lightning has become the second greatest meteorological calamity causing deaths in America ${ }^{[1-4]}$. Dlamini ${ }^{[5]}$ and Elson ${ }^{[6]}$ have also analyzed casualty features of lightning in Swaziland and UK. In order to master characteristics of lightning disaster and its principles of spatial and temporal distribution as well as conduct sound anti-thunder work, a lot of staff members in scientific research and prevention of lightning have made detailed analysis on characteristics and vulnerability of lightning disaster ${ }^{[716]}$. However, few reports have been made on characteristics of lightning disaster of Hainan Island.

Located in the northern part of tropics, with high temperature and high humidity, Hainan Island is not only influenced by tropical weather system but also encounters invasion of cold air. Severe convection weather is locally common, which is so intense as to cause disasters. Hainan
Island is one of the regions in China with the most frequent visits of lightning ${ }^{[17]}$. Nearly half of its cities and counties are plagued by thunderstorm for over 100 days annually [18 20]. Thunderstorm is the meteorological calamity second only to tropical cyclone in terms of lightning casualties and economic losses ${ }^{[21]}$.

Therefore, based on data of national compilation of lightning disasters (hereinafter referred to as compilation of lightning disasters), organized and compiled by Anti-lightning Management Office of China Meteorological Administration from 1999 to 2011, and according to the thunderstorm data from manual observation in 18 meteorological stations, lightning location data as well as Hainan provincial statistical yearbook data, the Article made statistical analysis on characteristics of spatial and temporal distribution of lightning disasters, lightning casualties and property losses in Hainan Island in the past 13 years from 1999 to 2011, providing some scientific basis and reference for anti-lightning work in Hainan.

\section{DATA}

The lightning disaster compilation has been compiled by the Lightning Protection Management Office of China Meteorological Administration, provinces and municipalities since 1997. The compilation is made once a year. Since 2002, Lightning Committee of China Meteorological Society was entrusted to undertake the lightning disaster data compilation. The compilation of lightning disasters in 1997 and 1998 was of slight significance for statistics due to inclusion of some typical lightning disasters only. The Article made statistical analysis on characteristics of lightning disasters in Hainan by making use of lightning disaster data compiled from 1999 to 2011. The statistics on lightning disasters in the Article was incomplete due to incomplete report and non-standardized forms on lightning disasters and failures of reports on lightning disasters or incomplete information. In order to make comparison with other research results, the Article also referred to lightning disasters with casualties as casualty accidents and lightning disasters without casualties as lightning disasters with damage.

Thunderstorm data from manual observation in 18 cities and counties' meteorological stations in Hainan Island were different from each other in terms of years of observation with Haikou with maximum years of manual observation data and Changjiang and Baoting with the minimum ones. Refer to Table 1 for data on thunderstorm days in cities and 
counties in Hainan Island. The statistics on the number of years was from the establishment of the station to 2011 with
61 years as the longest and 46 years as the shortest.

TABLE I. OBSERVED DATA ON THUNDERSTORM FROM 18 METEOROLOGICAL STATIONS IN HAINAN ISLAND

\begin{tabular}{cccccccccccc}
\hline No. & Station & $T_{\mathrm{d}} / \mathrm{d}$ & Number of years & No. & Station & $T_{\mathrm{d}} / \mathrm{d}$ & Number of years & No. & Station & $T_{\mathrm{d}} / \mathrm{d}$ & Number of years \\
\hline 1 & Haikou & 98.8 & 61 & 7 & Danzhou & 112.2 & 59 & 13 & Dongfang & 76 & 49 \\
2 & Wenchang & 89.6 & 53 & 8 & Qionghai & 84.8 & 59 & 14 & Ledong & 88.2 & 50 \\
3 & Chengmai & 121.5 & 53 & 9 & Qiongzhong & 102.1 & 56 & 15 & Baoting & 100.4 & 46 \\
4 & Lin'gao & 96.1 & 50 & 10 & Baisha & 112.5 & 53 & 16 & Wanning & 68.5 & 53 \\
5 & Ding'an & 109.0 & 49 & 11 & Wuzhishan & 109.9 & 53 & 17 & Lingshui & 80.6 & 56 \\
6 & Tunchang & 110.2 & 53 & 12 & Changjiang & 84.3 & 46 & 18 & Sanya & 60.2 & 51 \\
\hline
\end{tabular}

The lightning location network in Hainan was composed of 6 sub-stations, namely, Haikou, Sanya, Qionghai, Dongfang, Qiongzhong and Yongxing Island, which started debugging and operation since the second half of 2006. Its lightning location system was upgraded based on arrangement of China Meteorological Administration in 2010. The Article selected complete lightning location data of four years, namely, 2007-2008 and 2010-2011 and made statistics and analysis on characteristics of changes in monthly and daily distribution of lightning.

Hainan Provincial Statistic Yearbook was the source for population, GDP economic data and regional area in municipalities and counties in Hainan Island.

\section{ANALYSIS ON CHARACTERISTICS OF LIGHTNING DISASTERS}

\section{A. Overview of lightning disasters}

As shown in Table 2, a total of 727 lightning disaster accidents were reported in Hainan in a period of 13 years from 1999 to 2011, of which 176 were lightning casualty accidents and 551 were property loss accidents. They resulted in a total of 405 casualties, of which 157 were dead and 248 were injured. The ratio of casualties of lightning stroke was $1.58: 1$. Ronald ${ }^{[22]}$ believed that the ratio of casualties was an effective index for reflecting quality of data of casualties from lightning stroke. Generally, the ratio of casualties from lightning stroke was $5 \sim 10^{[23]}$ while Holle and others ${ }^{[24]}$ made assessment on impact of lightning stroke globally, inferring that a total of 24,000 people died and another 240,000 people were injured. Elson ${ }^{[6]}$, Cherington and others ${ }^{[25}$ analyzed records of lightning stroke in the UK and Colorado in the US, drawing a ratio of casualties from lightning stroke of 10:1. The research results of Ronald and others ${ }^{[2]}$ showed that the ratio of casualties from lightning stroke in the US from 1959 to 1994 was 2.54:1. And the ratio of casualties from lightning stroke in China from 1997 to 2006 was 0.96:1 $1^{[8]}$. A relatively lower ratio of casualties from lightning stroke may indicate underreported casualty accidents from lightning stroke. Through comparison with proof of death and hospital records, Kathleen and others ${ }^{[26]}$ found that $17 \%$ of death toll and $5 \%$ of injured population from lightning stroke were underreported in lightning disaster data in Michigan, the US.

TABLE II. STATISTICS OF LIGHTNING DISASTER ACCIDENT IN HAINAN ISLAND FROM 1999 TO 2011

\begin{tabular}{|c|c|c|c|c|c|c|}
\hline Year & $\begin{array}{l}\text { Total number } \\
\text { of lightning } \\
\text { disaster }\end{array}$ & $\begin{array}{c}\text { Number of } \\
\text { lightning disaster } \\
\text { with casualty }\end{array}$ & $\begin{array}{c}\text { Number of } \\
\text { lightning disasters } \\
\text { with damage }\end{array}$ & $\begin{array}{l}\text { Total lightning } \\
\text { casualty }\end{array}$ & Total death toll & $\begin{array}{c}\text { Total number of } \\
\text { injury }\end{array}$ \\
\hline 1999 & 29 & 5 & 24 & 13 & 4 & 9 \\
\hline 2000 & 21 & 10 & 11 & 24 & 9 & 15 \\
\hline 2001 & 32 & 13 & 19 & 34 & 11 & 23 \\
\hline 2002 & 61 & 21 & 40 & 55 & 28 & 27 \\
\hline 2003 & 88 & 19 & 69 & 40 & 16 & 24 \\
\hline 2004 & 63 & 27 & 36 & 70 & 25 & 45 \\
\hline 2005 & 48 & 21 & 27 & 46 & 15 & 31 \\
\hline 2006 & 44 & 11 & 33 & 22 & 9 & 13 \\
\hline 2007 & 90 & 18 & 72 & 58 & 15 & 43 \\
\hline 2008 & 107 & 12 & 95 & 19 & 13 & 6 \\
\hline 2009 & 88 & 14 & 74 & 18 & 9 & 9 \\
\hline 2010 & 47 & 4 & 43 & 5 & 2 & 3 \\
\hline 2011 & 9 & 1 & 8 & 1 & 1 & 0 \\
\hline Total & 727 & 176 & 551 & 405 & 157 & 248 \\
\hline
\end{tabular}

From Table 2, it was known that a total of 56 lightning disaster accidents happened in Hainan Island in average per year from 1999 to 2011. An average of 31.2 people were dead or injured per year due to lightning stroke, of which an average of 12.1 people died from lightning stroke and 19.1 people were injured from lightning stroke. If calculating with 8.67 million people of Hainan Province in the $6^{\text {th }}$ Nationwide Population Census in 2010, about 1.4 people per million people died from lightning stroke on average per year, which was 2.6 times of that nationwide ${ }^{[8]}, 3.3$ times of the US ${ }^{[23]}$ and 27.8 times of the $\mathrm{UK}^{[23]}$. 


\section{B. Spatial and temporal distribution of lightning disasters}

\section{1) Characteristics of inter-annual change}

The inter-annual change for lightning disasters and lightning casualty in Hainan Island from 1999 to 2011 were seen in Figure 1. In early years from 1999, there was a huge rise in total lightning disaster, number of lightning disasters with casualty, lightning disasters with damage as well as lightning casualty, likely due to false appearance ${ }^{[6]}$ from incomplete and nonstandard data source for primary statistics in the initial stage of statistics on lightning disasters. In recent years, there was a clear downturn in number of lightning disasters and casualties. Ronald ${ }^{[22]}$ believed that a reduction in the death toll per million from lightning stroke was related to factors such as better warning and forecast on thunder and lightning, more advanced medical care and emergency transportation and wider application of enclosed metal-shell automobiles.

Through analysis on data of thunderstorm days in Hainan Island, it was found that thunderstorm days in municipalities and counties were inclined to a decline. However, in recent years, inter-annual thunderstorm days were not in clear fall like lightning disasters. Take inter-annual thunderstorm days in Haikou as an example. Figure 2 showed inter-annual thunderstorm days in Haikou. Seen from Figure 2a, it was found that inter-annual thunderstorm days in Haikou gradually decreased in overall. In contrast, seen from Figure 2b, it was found that there was no clear fall in inter-annual thunderstorm days in recent years. There was no sound consistency between number of lightning disasters and number of inter-annual thunderstorm days, indicating that lightning disasters in Hainan Island were not merely relevant with thunder and lightning, which was consistent with research results of Guo Hu and others [10]. Thunder and lightning were just one of disaster-inducing factors. Lightning disasters were also influenced by other factors (such as population density, economic characteristics and lightning-proof measures etc.).

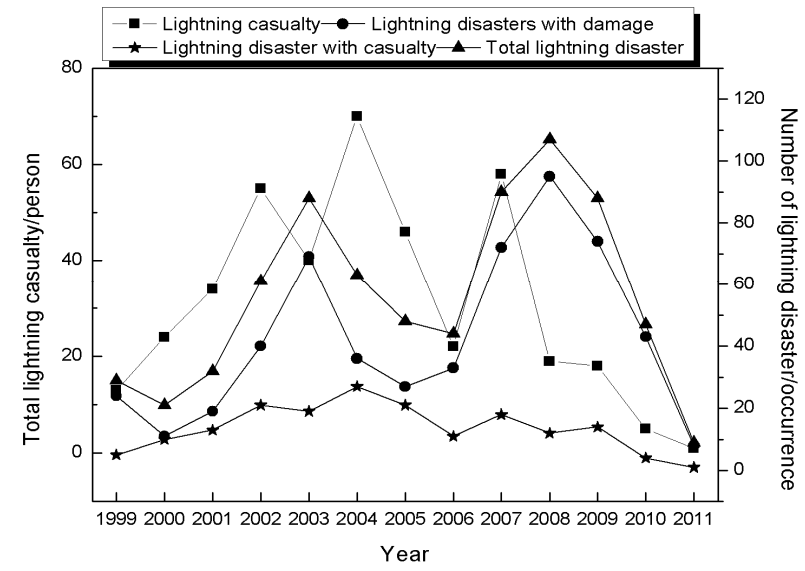

Figure 1. Inter-annual change of lightning disaster and lightning casualty in Hainan Island
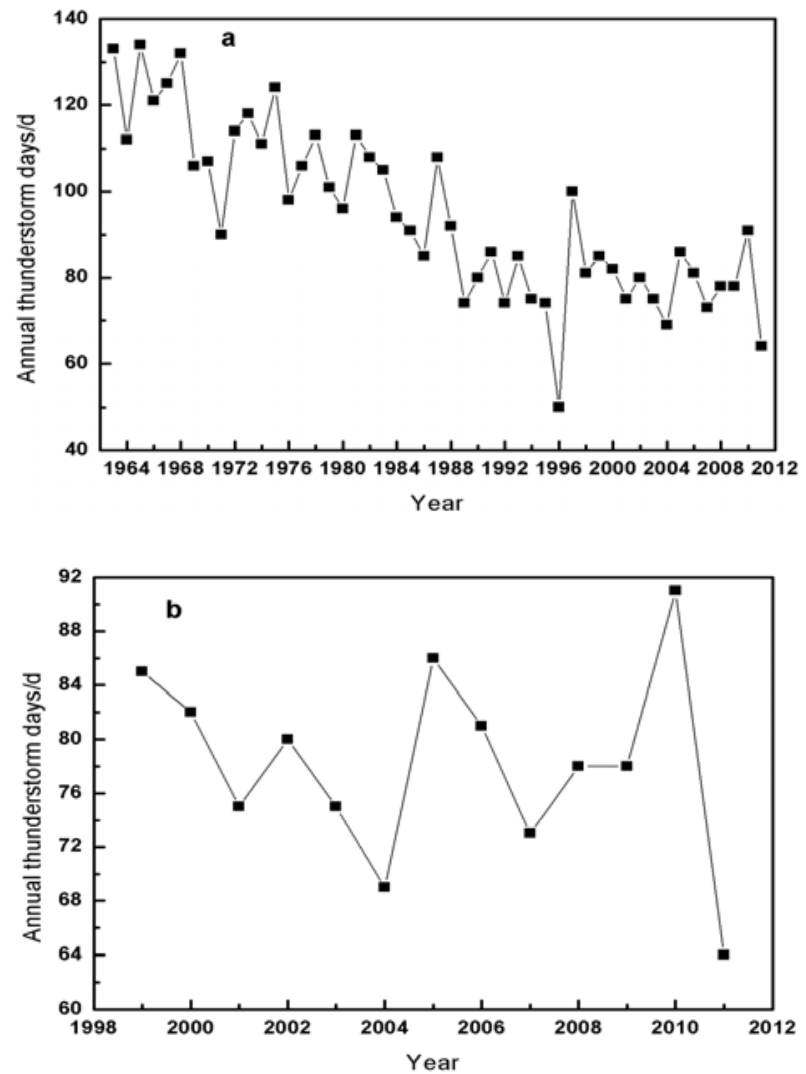

Figure 2. Inter-annual change of thunderstorm days in Haikou

\section{2) Characteristics of monthly change}

The monthly distribution of lightning disasters in Hainan Island was shown in Figure 3, in which lightning strikes was drawn from statistics on 4-year data (2007, 2008, 2010 and 2011) on Hainan lightning location system in the form of percentage of all months. Lightning disaster accidents occurred from February to November given no lightning disasters in January and December. A majority of lightning disaster accidents happened from April to September, accounting for $96.5 \%$ of total lightning disaster accidents; period from May to August was the peak for lightning disaster throughout the year, accounting for $77.8 \%$ of lightning disaster accidents in the year; maximum number of lightning disaster accidents occurred in June, accounting for over $1 / 5$ of total lightning disasters. Lightning casualty from lightning disasters were distributed from April to October. Lightning strikes happened in four seasons in Hainan Island, mainly from April to October with the period from May to September as the high-occurrence season. Monthly distribution of lightning disasters in Hainan was consistent with seasonal distribution principle of lightning strikes in Hainan. 


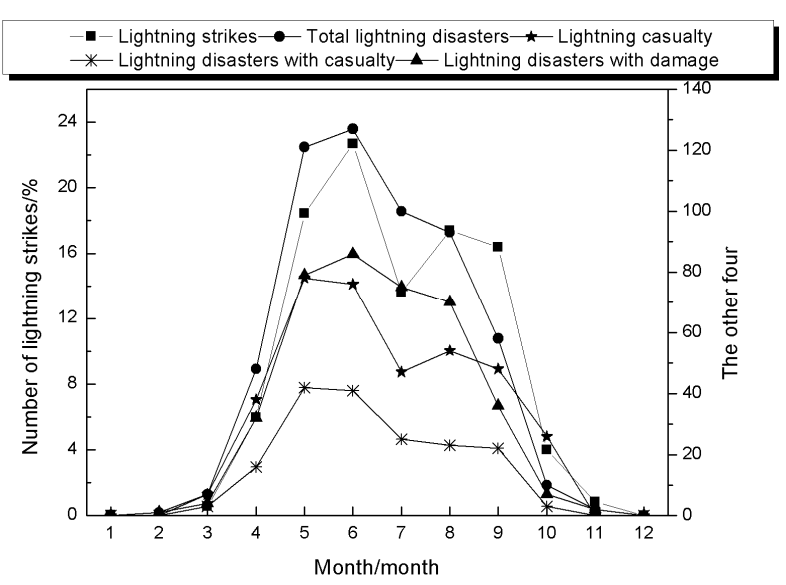

Figure 3. Monthly change of lightning disaster and lightning strikes in Hainan Island

\section{3) Characteristics of daily change}

Figure 4 showed daily distribution of lightning disasters in Hainan Island, in which lightning strikes was drawn from statistics on 4-year data (2007, 2008, 2010 and 2011) on Hainan lightning location system in the form of percentage of all months. As shown in Figure 4, there were lightning strikes and lightning disaster accidents in Hainan Island in 24 hours a day. The distribution of lightning casualty from lightning strikes and lightning disasters was consistent with each other, in the unimodal shape with 13:00pm-18:00pm in the afternoon as the peak and 15:00pm-16:00pm as the period of maximum lightning strikes and lightning disaster accidents, which was the moment of maximum casualties from lightning disasters.
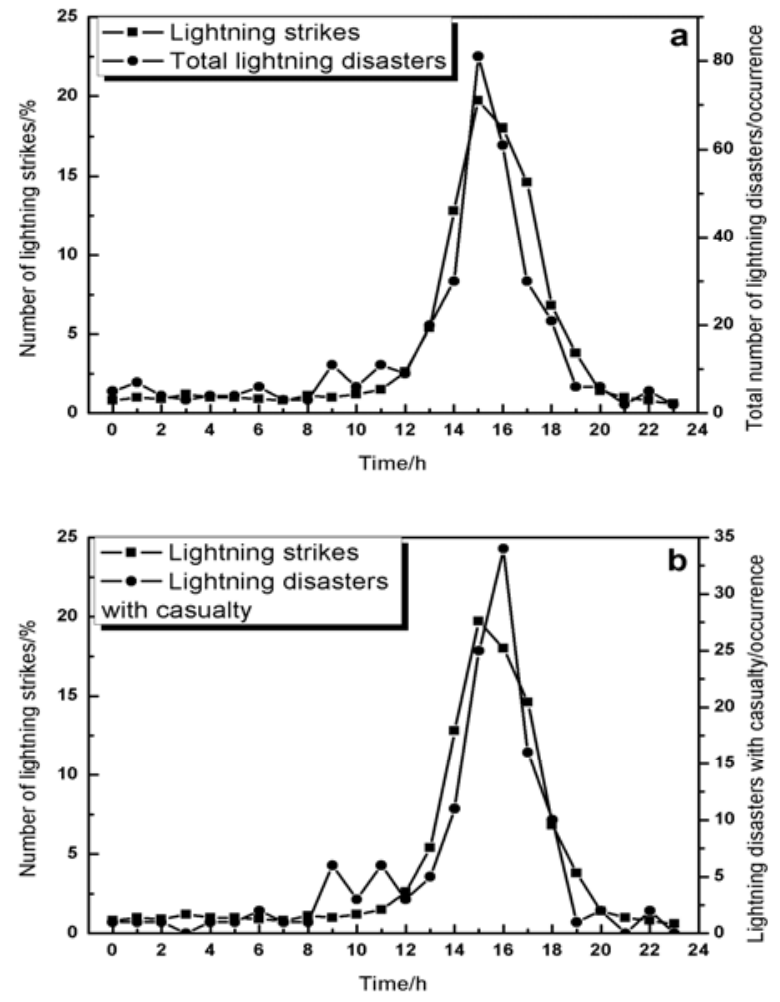
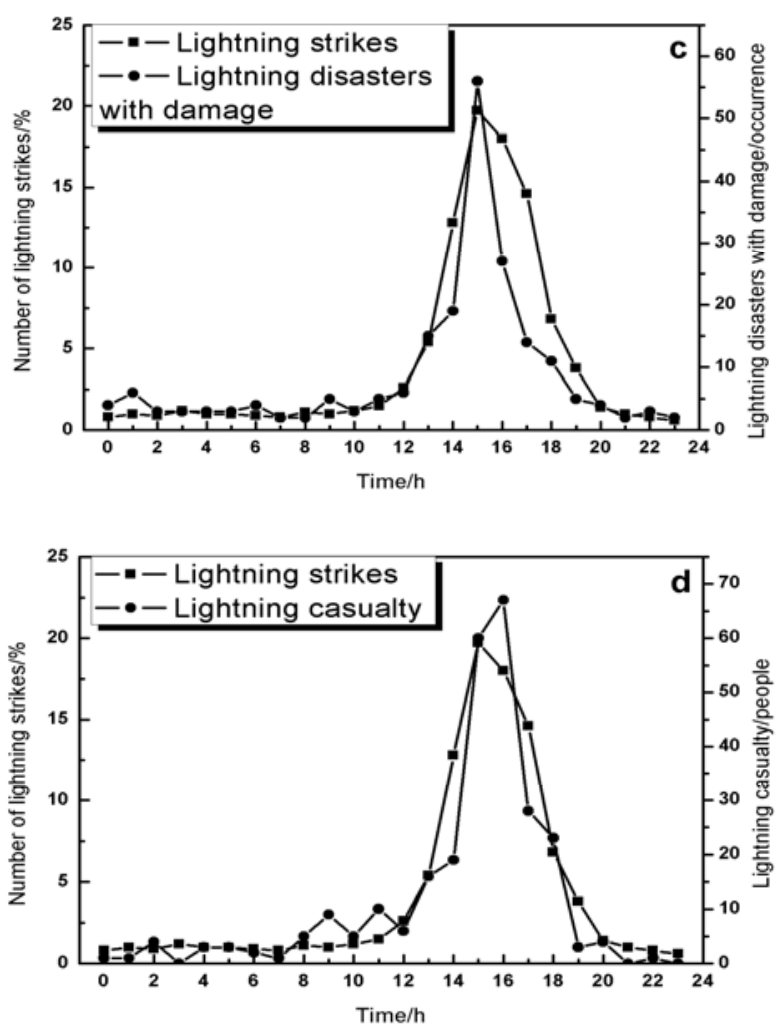

Figure 4. Daily change of lightning disasters in Hainan Island: (a) total lightning disasters; (b) lightning disasters with casualty; (c) lightning disasters with damage; (d) lightning casualty

\section{4) Characteristics of spatial distribution}

The spatial distribution of thunderstorms and lightning disasters in Hainan Island was shown in Figure 5, in which isoline represented inter-annual average thunderstorm days in municipalities and counties in Hainan Island from 1966 to 2011 and region colors represented total lightning disasters from 1999 to 2011. Thunderstorm days in Hainan Island decreased from the middle to the coast with more thunderstorm days in the middle and north and less thunderstorm days in the south. Chengmai County was of the maximum thunderstorm days with a total of 121.5 days. Sanya City was of the minimum thunderstorm days with a total of 60.2 days. Lightning disasters in Hainan Island mainly happened in Haikou in its north, Qiongzhong in its middle as well as Wanning and Qionghai off the eastern coast while few lightning disasters occurred in other northern municipalities and counties, in the west and south. The number of lightning disasters in Hainan Island failed to match the intensity of thunderstorm days, indicating once again that the occurrence of disasters was not only relevant to disaster-inducing environment but also vulnerability of hazard-bearing body. 


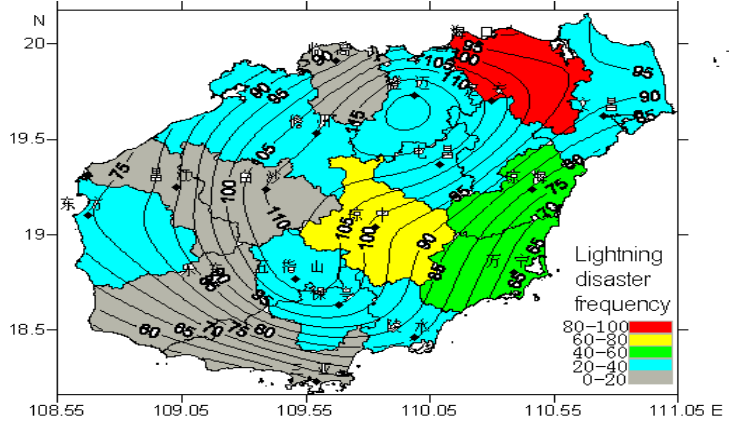

Figure 5 Spatial distribution of annual average thunderstorm distribution of lightning disasters

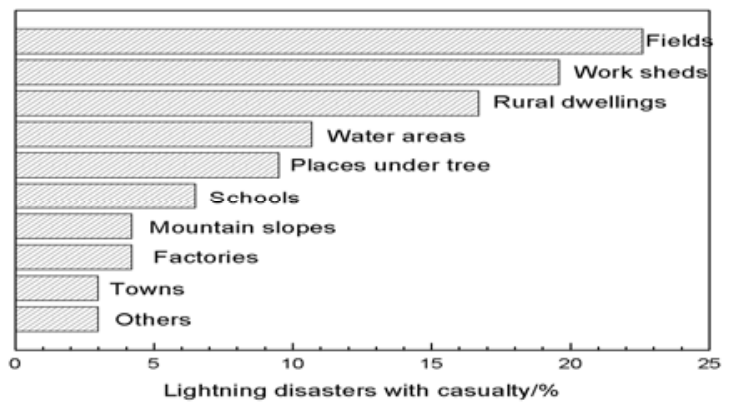

Figure 6 Area days and lightning disasters in Hainan Island with casualty

\section{Features of casualties caused by lightning strikes}

Each author has his/her own classification for casualties and property damages caused by lightning strikes and the Article classifies the places with lightning disasters into the following categories from the point of view of lightning protection and disaster reduction and according to the occurrence situation of lightning disaster accidents and occurrence frequency of lightning disasters so as to caution people to try to keep away from these highly dangerous places with lightning strikes in case of thunderstorms.

There were totally 176 casualties during lightning disaster accidents from 1999 to 2011 in Hainan Province, among which 168 accidents were with specific place information. Fig. 6 is the area distribution of lightning disasters with casualty. From Fig 6, it can be seen that wild fields and other open places (22.6\%) and orchards, plantations, wild work sheds, simply-equipped sheds, thatched cottages, log cabins and tile-roofed houses, etc. in rural areas and suburbs (19.6\%) are the most vulnerable to lightning disasters with casualty; villages, farms and their dwellings and other buildings and structures (16.7\%) are second to the above-mentioned places; the next is rivers, sea, ponds with fish and shrimp, etc. or water-land junctions (10.7\%); big trees are also frequently seen lightning disasters with casualty (9.5\%); while schools, mountains, mountain slopes, slopes, factories and towns, etc. have relatively less lightning disasters with casualty.

Lightning disasters with casualty and the casualties caused therein mainly happen in rural areas. As known from the above analysis, lightning disaster accidents of Hainan Province mainly happen between 13:00pm to 18:00pm from
April to September, which is the busy farming season. Afternoon is the time when farmers are working in the wild fields. As they have no time to elude thunderstorms, they may take shelter from the rain under nearby trees, simply-equipped work sheds, thatched cottages, etc., which are prone to lighting strike accidents or casualties. There are many people living on fishing and pond farming in Hainan, since the Province is surrounded by sea and crisscrossed with rivers. Places at riverside and seaside or water-land junctions, etc. with soil resistivity of sudden change are liable to cause lightning strikes. Therefore, lightning disasters with casualties frequently happen at these places. In addition, rural residents are prone to casualties once there are lightning strikes because most of them are without lightning-proof measures and farmers have weak awareness of lightning protection and lack lightning protection knowledge.

\section{Property damage features of lightning strike}

Statistical analysis of the distribution situation of lightening disaster accidents and the distribution features of direct economic losses caused therein is carried out according to different fields for the lightning disasters with property damages, which are provided with specific numerical values of direct economic losses. The Article divides the occurrence fields of lightening disaster accidents with property damages into seven categories, i.e., industries, colleges, hotels, enterprises, organs, cities and towns and rural areas. Industries refer to power industry, petrochemical industry, communications industry, transportation industry and financial industry; colleges refer to universities and technical colleges, scientific research institutions and middle and primary schools; hotels refer to hotels, guesthouses, rest houses, holiday villages and other places offering accommodation, catering and recreation; enterprises refer to hotels and companies and factories not included in the above five industries; organs refer to office spaces and dormitory residential areas of municipal and county governments, public institutions, troops, broadcasting and TV stations, hospitals and other units; cities and towns refer to buildings and structures in cities above town level and other than college, hotel, enterprise and organ, and rural areas refers to rural dwellings and other civil architectures or facilities located in rural areas.

Fig. 7 is the distribution of lightning strike accidents with property damages in different fields and the direct economic loss situation. From this figure, lightning disaster accidents with property damages in Hainan Province most frequently happen in five industries such as power industry and petrochemical industry, accounting for $22.2 \%$ of the total lightning disaster accidents with property damages, among which power industry accounts for about half, petrochemical industry, communications industry and financial industry all respectively account for over 3.\%, while transportation industry accounts for less than $1 \%$; the second prone to lightening disasters with property damages are rural areas and organs, both making up about 20\%; and the next is the enterprise, accounting for $10.3 \%$; the frequency of lightning disaster accidents with property 
damages in colleges, hotels and cities and towns is almost the same, all being below $10 \%$ but approximating $10 \%$. The direct economic losses caused by lightening disaster accidents with property damages are mainly concentrated in hotels, cities and towns, industries and organs: hotels accounting for over one-third (34.7\%) of the total direct economic losses, the next being the cities and towns, accounting for nearly one-fifth of the total direct economic losses, the next being the industries and organs, their direct economic losses being equal, both accounting for over $13 \%$, while the direct economic losses of enterprises, rural areas and colleges account for a small portion. Lightening disaster accidents with property damages and direct economic losses caused therein mainly happen in cities, and one main reason for lightening disaster accidents with property damages is absent of lightening protection devices and imperfect lightning protection devices. In 150 lightening disaster accidents, 32 were due to the absence of lightning devices and 31 were due to unqualified or imperfect lightning devices as found in the statistics of lightning disaster accidents with property damages from 2007 to 2011.
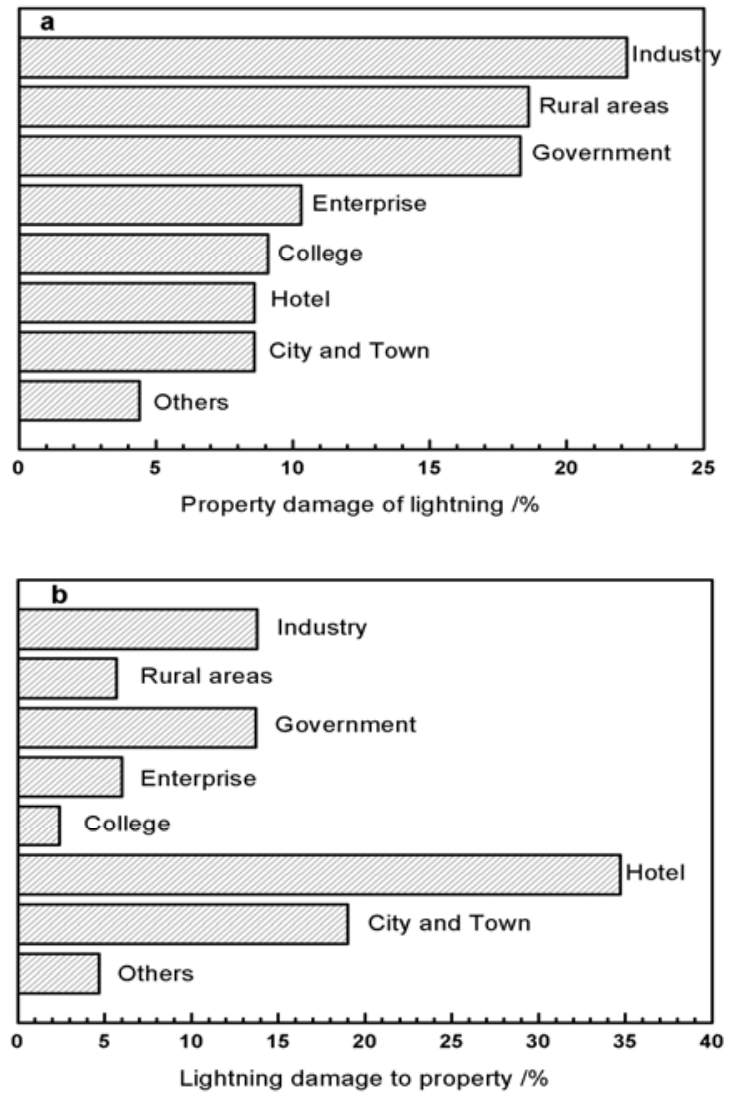

Figure 7. Distribution of characteristics of lightning damage

\section{E. Analysis of relevant factors of lightning disasters}

As known from the above analysis, the occurrence time distribution of lightning disasters is consistent with the activity rule of lightning; however, the spatial distribution of lightning disasters is not so consistent with the spatial distribution of lightning activities. It is known from the science of natural disasters, lightning disasters are not only relevant to lightning activities that forms lightning disasters, but also relevant to the vulnerability of hazard-bearing bodies. The Article selects life vulnerable modulus and economy vulnerable modulus which represent the factors of vulnerability of hazard-bearing bodies to analyze the relation between lightning disasters and vulnerability of hazard-bearing bodies.

Life vulnerable modulus refers to the number of people per square kilometer ${ }^{[27]}$, with the unit being 10,000 persons/square kilometers. The number of population in each city and county of Hainan comes from the $6^{\text {th }}$ National Population Census in 2010 and the regional area comes from the statistical yearbook of Hainan Province. From Fig. 8 of the relation among lightning disasters with casualty, life vulnerable modulus and thunderstorm days, the correlation between lightning disasters with casualty and thunderstorm days is not obvious, while the number of lightning disasters with casualty, number of casualties caused by lightning disasters and life vulnerable modulus feature relatively good consistency: the number of casualties caused by lightning disasters with casualty and life vulnerable modulus are positively correlated with each other, the correlation coefficient being 0.67.

Economy vulnerable modulus refers to the economic aggregate per square kilometer ${ }^{[27]}$, with the unit being 100 million Yuan/square kilometer. The regional area and economic aggregate of each city and county of Hainan Province both come from the statistical yearbook of Hainan Province and the Article takes the average value of economic aggregate from 1999 to 2009. The relation among lightning disasters with property damages, economy vulnerable modulus and thunderstorm days is shown in Fig. 9: there is not so good correlation between lightning disasters with property damages and the economic losses caused therein, and thunderstorm days; the correlation of lightning disasters with property damages and the economic losses caused therein, with economy vulnerable modulus is obviously better than that with annual thunderstorm days, which is the same with the results of lightning disasters with casualty as analyzed above, further explaining that the lightning disasters of Hainan Island is not only relevant to lightning activities but also relevant to the factors of the population distribution and economic situation, etc. of Hainan Island. 


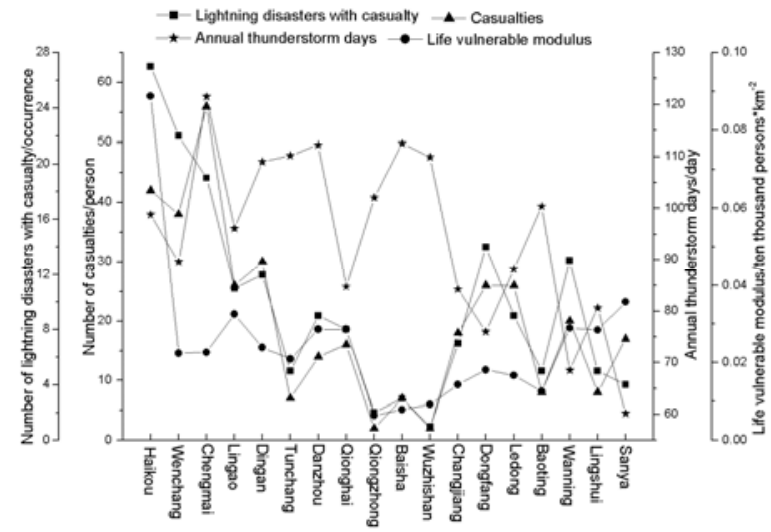

Figure 8. Comparison of lightning disasters with casualty, thunderstorm day and life fragile module

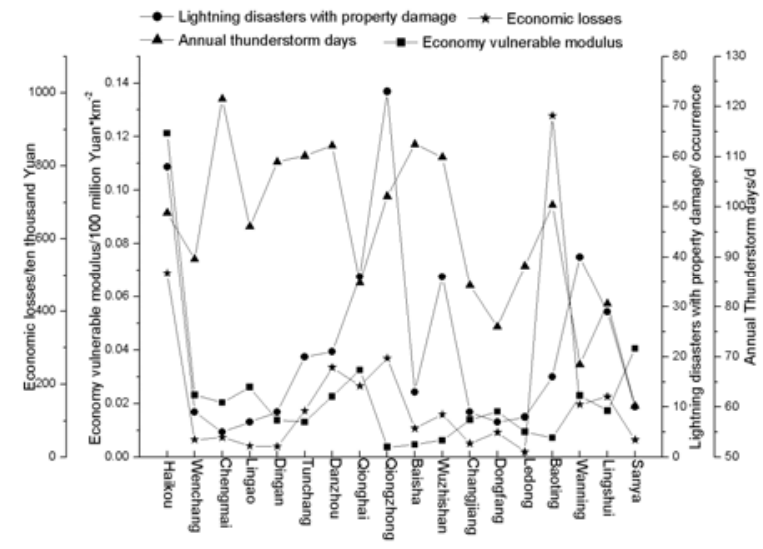

Figure 9. Comparison of lightning disasters with damage, thunderstorm day and economic vulnerability module

\section{CONCLUSION AND DISCUSSION}

As known from the above analysis, the spatial distribution of lightning disasters of Hainan Island is not so consistent with the spatial distribution of thunderstorm activities. Through analysis of the spatial and temporal distribution of the natural lightning and lightning disasters of Beijing City, Guo Hu et al. ${ }^{[11]}$ also found that the natural lightning of Beijing City was not so consistent with the regional distribution of lightning disasters: the north remote suburbs with relatively more natural lightning had no frequent lightning disasters while the urban areas with relatively less natural lightning was the region with frequent lightning disasters. The research results of Ma Ming et al. ${ }^{[9]}$ show that the number of lightning disaster accidents and number of casualties of lightning disasters are positively correlated with the disaster-inducing factor (lightning activities) and hazard-bearing bodies (current situation of population and economic development) of different regions of our country. Ma Ming divided the number of casualties of lightning disasters of 31 provinces, municipalities and autonomous regions of mainland China into 4 levels according to quartering and found by comparison with the geographical distributions of lightning density of our country that the both were relatively consistent in the regional correspondence at 4 levels: the region with high lightning density was the region with high level of lightning disasters. The above analysis shows that lightning disasters and lightning activities show relatively good consistency in relative big spatial scales while in small spatial scales, they do not show a good consistency. So is the bigger spatial scale, the better correlation of lightning disasters and lightning activities? Or how big is the spatial scale at least to achieve relatively good consistency of lightning disasters and lightning activities? In addition, the not so good consistency among thunderstorm days, lightning density and spatial distribution of lightning disasters in small scales (such as Hainan Island and Beijing City) explains that other more effective risk division indexes should be sought while carrying out lightning risk division for certain provinces and cities, or the weights of thunderstorm days and lightning density in each index of the existing lightning risk division should be reconsidered.

Statistical analysis of the lightning disaster features of Hainan Island in 13 years is carried out by using the compilation data of lightning disasters, manually observed thunderstorm data, lightning positioning data and data of statistical yearbook of Hainan Province during 1999 to 2011, with the main results as follows:

I. Totally 727 lightning disaster accidents were reported, with 405 casualties: therein 157 deaths, 248 injuries, ratio of injury versus death being 1.58:1. There were about 1.4 persons dead due to lightning strikes in every million persons every year in Hainan, being higher than the national average value and even higher than that of the U.S. and UK.

II. Most of lightning disaster accidents occurred during April to September, with May to August being the peak in annual lightning disaster occurrence. The daily distribution of lightning disaster accidents took on single peak, with $13: 00 \mathrm{pm}$ to $18: 00 \mathrm{pm}$ being the peak period of lightning disaster accidents, and 15:00pm and 16:00pm being the hours with the most frequent lightning disasters. Haikou and Qiongzhong were the most frequent in lightning disaster accidents, and Chengmai and Baisha were the highest in annual thunderstorm days. The occurrence time of lightning disaster accident was consistent with the activity rule of lightning; however, lightning disaster accidents was not so consistent with the spatial distribution of annual thunderstorm days.

III. Lightning disaster accidents with casualties mainly happened at wild fields and other open spaces and inside simple work sheds, thatched cottages, log cabins and tile-roofed houses of plantations; the next was inside simple buildings of rural areas, farms and the dwellings therein; lightning disasters were easy to occur at rivers, sea, ponds with fish and shrimp, etc. or water-land junctions and places under big trees.

IV. The five industries of power industry and petrochemical industry, village and organ, etc. saw the most frequent lightning disaster accidents with property damages; direct economic losses caused by lightning disaster accidents with property damages were concentrated in hotel, city and town, five industries and organs. 
V. The respective correlation between lightning disasters with casualty, lightning disasters with property damages, and thunderstorm days was not obvious; however, the correlation respectively between lightning disasters with casualty, lightning disasters with property damages, and life vulnerable modulus and economy vulnerable modulus took on relatively good positive correlation. Lightning disasters were not only relevant to the lightning activities but also relevant to the population distribution, economic situation and other factors of Hainan Island.

\section{V.ACKNOWLEDGMENT}

Thanks for the instruction for modification proposed by Zhang Yijun, a researcher of Chinese Academy of Meteorological Sciences, for the Article.

\section{REFERENCES}

[1] Roeder W P, Holle R L, Cooper M A, et al. Lessons learned in communicating lightning safety effectively[C]//4 ${ }^{\text {th }}$ International Lightning Meteorology Conference, 2012: 4-5.

[2] Ronald L H, Raul E L. Lightning casualties and damages in the United States from 1959 to 1994 [J]. Journal of Climate, 2000, 13(19): 3448-3464.

[3] Lopez R E, Holle R L. Changes in the number of lightning deaths in the United States during the twentieth century[J]. Journal of climate, 1998, 11(8): 2070-2077.

[4] López R E, Holle R L. Fluctuations of lightning casualties in the United States: 1959-1990[J]. Journal of Climate, 1996, 9(3): 608-615.

[5] Dlamini W M. Lightning fatalities in Swaziland: 2000-2007[J]. Natural Hazards, 2009, 50(1): 179-191.

[6] Elson D M. Deaths and injuries caused by lightning in the United Kingdom: Analyses of two databases [J]. Atmospheric Research, 2001, 56: 325-334.

[7] Mei Zhen, Chen Shuiming, Gu Qinwei, et al. Statistic of lightning accidents during 1998-2004 in China [J]. High Voltage Engineering, 2007, 33(12): 173- 176. (In Chinese)

[8] Ma Ming, Lu Weitao, Zhang Yijun, et al. Characteristics of lightning exposure in China from 1997 to 2006 [J]. Journal of Applied Meteorological Science, 2008, 19(4): 393- 400. (In Chinese)

[9] Ma Ming, Lu Weitao, Zhang Yijun, et al. Analysis of lightning disasters in China and their correlative factors [J]. Advances in Earth Science, 2008, 23(8): 856-865. (In Chinese)

[10] Gao Yi, Zhang Yijun, Zhang Wenjuan, et al. Characteristics of lightning casualties and vulnerability evaluation regionalization in China [J]. Journal of Applied Meteorological Science, 2012, 23(3): 298- 303. (In Chinese)

[11] Guo Hu, Xiong Yajun, Fu Zongyu, et al. Temporal spatial characteristics of lightning activity and lightning disaster over
Beijing [J]. Meteorological Monthly, 2008, 34(1):12-17. (In Chinese)

[12] Wu Mengheng, Tian Yanting, Cui Haihua, et al. Statistical analysis of characteristics of lightning disaster in Hebei 2003 to 2008 [J]. Journal of Natural Disasters, 2010, 19(1):21-25. (In Chinese)

[13] Zhou Fangyuan, Xiao Wenan. Distribution characteristics analysis of lightning disaster in Anhui province during recent ten years [J]. Journal of Anhui Agri. Science, 2010, 38(4):1908-1911. (In Chinese)

[14] Guo Hu, Xiong Yajun. Vulnerability analysis, evaluation and vulnerability zoning of lightning disaster in Beijing [J]. Journal of Applied Meteorological Science, 2008, 19(1):35-40. (In Chinese)

[15] Wang Hui, Deng Yong, Yin Liyun, et al. Vulnerability analysis and zoning of lightning disaster in Yunnan province [J]. Meteorological Monthly, 2007, 33(12):83-87. (In Chinese)

[16] Zhang W, Meng Q, Ma M, et al. Lightning casualties and damages in China from 1997 to 2009[J]. Natural Hazards, 2011, 57(2): 465-476.

[17] Yuan Tie, Qie Xiushu. Spatial and temporal distributions of lightning activities in China from satellite observation [J]. Plateau Meteorological, 2004, 23(4):488-494. (In Chinese)

[18] Gao Yi, Chen Huilin, Lao Xiaoqing, et al. Analysis of environmental characteristics of thunderstorm activities at Wenchang Rocket Launching site in Hannan Province [J]. Journal of Natural Disasters, 2012, 21(4):182-189. (In Chinese)

[19] Guo Dongyan, Xin Jiwu, Wu Sheng'an, et al. Climate changes related to thundstorm days in Hainan and analysis of atmospheric circulation background [J]. Meteorological Science and Technology, 2008, 36(4):404-409. (In Chinese)

[20] Lao Xiaoqing, Gao Yi, Wu Hai, et al. Preliminary analysis on lightning characteristics over Hainan Island in 2007 [J]. Journal of Meteorological Research and Application, 2009, 30(2):90-92. (In Chinese)

[21] Wen Kegang, Wu Yanjun. Chinese meteorological disasters enchiridion Hainan part [M]. Beijing: China Meteorological Press, 2008:176-178. (In Chinese)

[22] Ronald L H. Annual rates of lightning fatalities by country[C]// 20th International Lightning Detection Conference, Tucson, 2008, 21-23.

[23] Rakov V A, Uman M A. Lightning: Physics and effects [M]. Cambridge: Cambridge University Press, 2003.

[24] Holle R L, Lopez R E. A comparison of current lightning death rates in the U.S. with other locations and times[C]// Intl. Conference on Lightning and Static Electricity, Blackpool, England, 2003.

[25] Cherington M, Walker J M, Boyson M, et al. Closing the gap on the actual numbers of lightning casualties and deaths[C]// 11th Conference on Applied Climatology, Dallas, TX, 1999, 379-380.

[26] Kathleen M S, Carl F O. Some causes for lightning data inaccuracies: the case of Michigan [J]. Bulletin of American Meteorological Society, 1999, 80(9): 1883-1891.

[27] Gao Yi, Meng Xiaoliang, Lao Xiaoqing. Cluster analysis-based vulnerability risk zoning of lightning disaster in Hainan Island [J]. Journal of Natural Disasters, 2013, 22(1):175-182. (In Chinese) 